\title{
The usefulness of VSM-based representations in organisational work
}

\section{Markus Brönnimann}

\author{
University of St. Gallen, \\ Dufourstrasse 50, 9000 St. Gallen, Switzerland \\ E-mail: markus.broennimann@unisg.ch
}

\begin{abstract}
This contribution tries to apply the Viable System Model (VSM) in a 'useful' way from the viewpoint of a practitioner. The system examined is the University of St. Gallen. This case study discusses the potential of a VSM-based view of an organisation, helping to analyse the way such an organisation actually works by pointing out actual problems with precision, while also acknowledging the limits of this model's application. This common understanding is an important groundwork for the successful implementation of a strategy. This paper demonstrates the considerable advantage of working with VSM. It is an effective and productive model.
\end{abstract}

Keywords: practical application of VSM; organisational charts; analysis of organisations; design of organisations; organisation and administration of universities.

Reference to this paper should be made as follows: Brönnimann, M. (2008) 'The usefulness of VSM-based representations in organisational work', Int. J. Applied Systemic Studies, Vol. 1, Nos. 1/2, pp.177-192.

Biographical notes: Markus Broennimann is Director of Administration of the University of St. Gallen. He holds a Degree in Business Administration of this university. He worked in a industrial company as head of quality assurance, later as Head of the IT-Department. For seven years, he worked as a Consultant and Lecturer at the Management Zentrum St.Gallen. He focused on strategy, organisation and managerial effectiveness. At the university he was responsible for the implementation of the Bologna Declaration in the administration.

\section{General overview}

The field of basic education at the University of St. Gallen had to undergo massive changes in the past four years. This transition period will presumably continue for the next $2-3$ years. The trigger for these broad organisational changes was the consequent and radical implementation of the so-called Bologna-System ${ }^{1}$ (the introduction of BA and MA Degrees). This project is called 'Neue Konzeption Lehre'2 (NKL). The changes are fundamental because all domains of basic education are affected.

In such a situation powerful tools and models are needed if one is to identify, design, and communicate the consequences of the change and the ways of accomplishing the aims of the NKL. 
The nature of this situation naturally recommends the Viable System Model (VSM), which is a universal model for the diagnosis and design of organisations under the aspects of viability and development.

\section{Present status of the discussions}

System-oriented management and management cybernetics have a long tradition at the University of St. Gallen. Therefore the 'St. Galler Management Modell' (Ulrich, 2001; Rüegg-Stürm, 2002) refers to this basis and translates these concepts into a language that can be understood by executives.

\subsection{Business activities of the university}

On this foundation the management of the University of St. Gallen has divided its business activities into four 'Strategic Business Fields' (SBF). The university is therefore active in the following four SBFs:

- Basic education

- Research

- Executive education

- Services (of our institutes).

The SBFs are systems 1 according to the VSM-logic. They have clear-cut markets and provide precisely defined (or definable) market services.

The fact that the mapping of systems 1 to the SBFs works so well shows that the division was carried out following reasonable criteria (the four SBFs/systems seem to be viable). This way of looking at a university, however, is quite unusual. Normally such an institution is seen as being more resource- or input-oriented. Taking this tendency into account, our university management tried to integrate the two perspectives, which led to the following organisational chart (Figure 1).

\subsection{Organisational chart}

The previous structure at Sankt Gallen was grounded only on the resource-based view. Therefore, the market- or product-view had to be introduced. While the dean of a department is primarily focused on his academic profession and its human resource-wise implementation, the program manager has a totally different perspective.

The program manager may not restrict his outlook to his faculty alone. He must also take into account what kinds of knowledge, in what combinations, the graduates of his program must take with them to be of maximal use as professionals in organisations. The program manager (or the person in charge of the program) is therefore not only the agent for his faculty, but also - and above all - is a product manager who has to 'work a market'.

For the effective implementation of the organisational idea (through an effective combination of resource-based and market-oriented views) the chosen illustration is not adequate, showing a number of insufficiencies: 
- The activities of the institutes, which acquire and account for a respectable part of the university's budget, are not represented in this illustration.

- The SBF basic education is split again, so that the recursions are now 'mixed up'.

- The administration, as the 'backbone' of the university, is not visible in the organisational chart.

- The detailed structure or 'inner parts' of the programs, very complex, are not mentioned in the diagram.

We asked ourselves how we would be able to eliminate these insufficiencies without destroying the idea of combining input and output.

Figure 1 Organisational chart university of St. Gallen

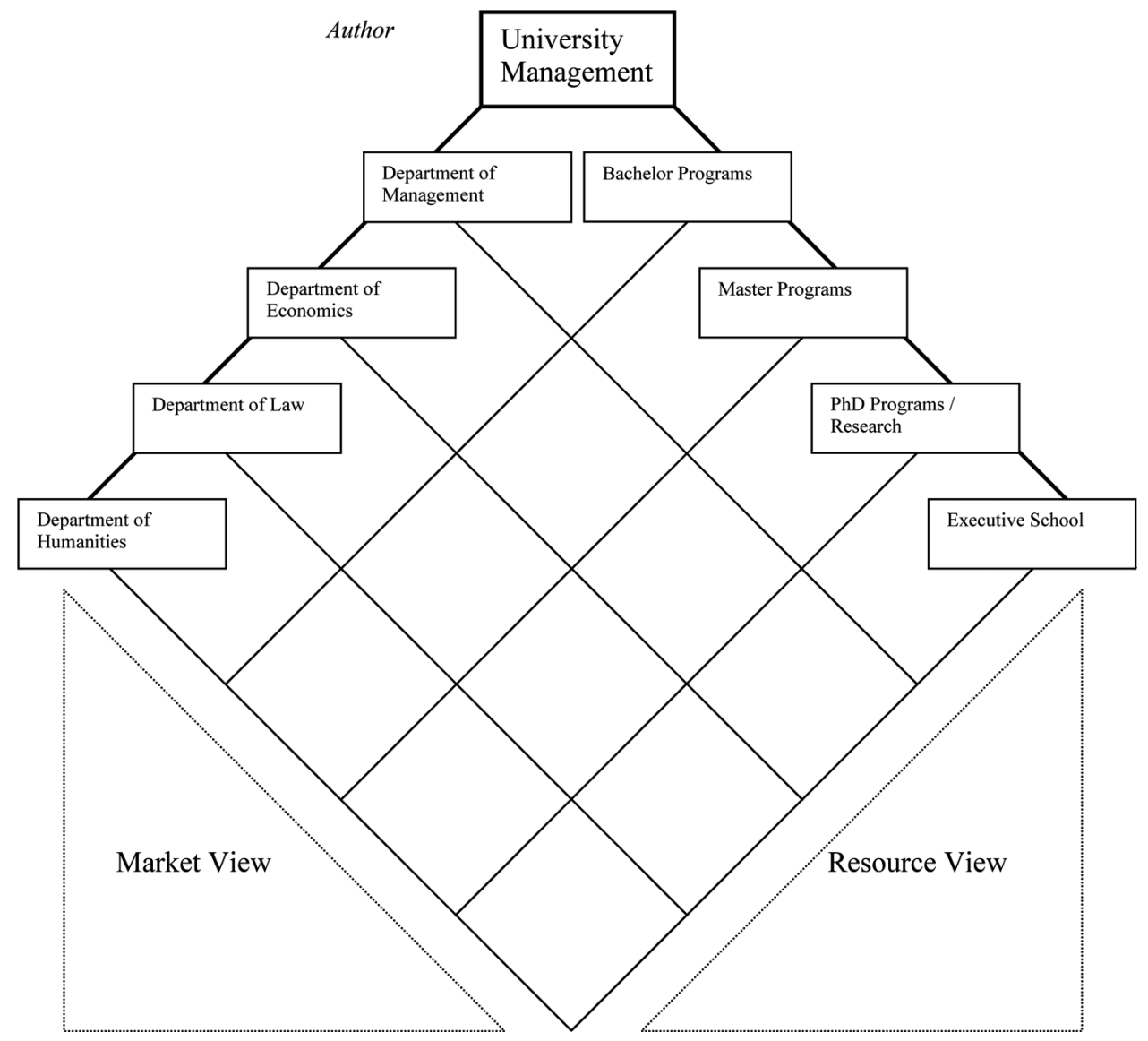

\section{VSM-based representation}

Even when the changes induced by the Bologna process pertain only to basic education, we began representing the organisation following the logic of $\mathrm{VSM}^{3}$ on the level of the university as a whole (Figure 2). This choice followed from the reaction of a part of 
the university's management team, which had the impression that previous representations of the organisational structure were close enough to reality to be able to discuss the real problems of the organisation.

Figure 2 VSM-based representation of the University of St. Gallen

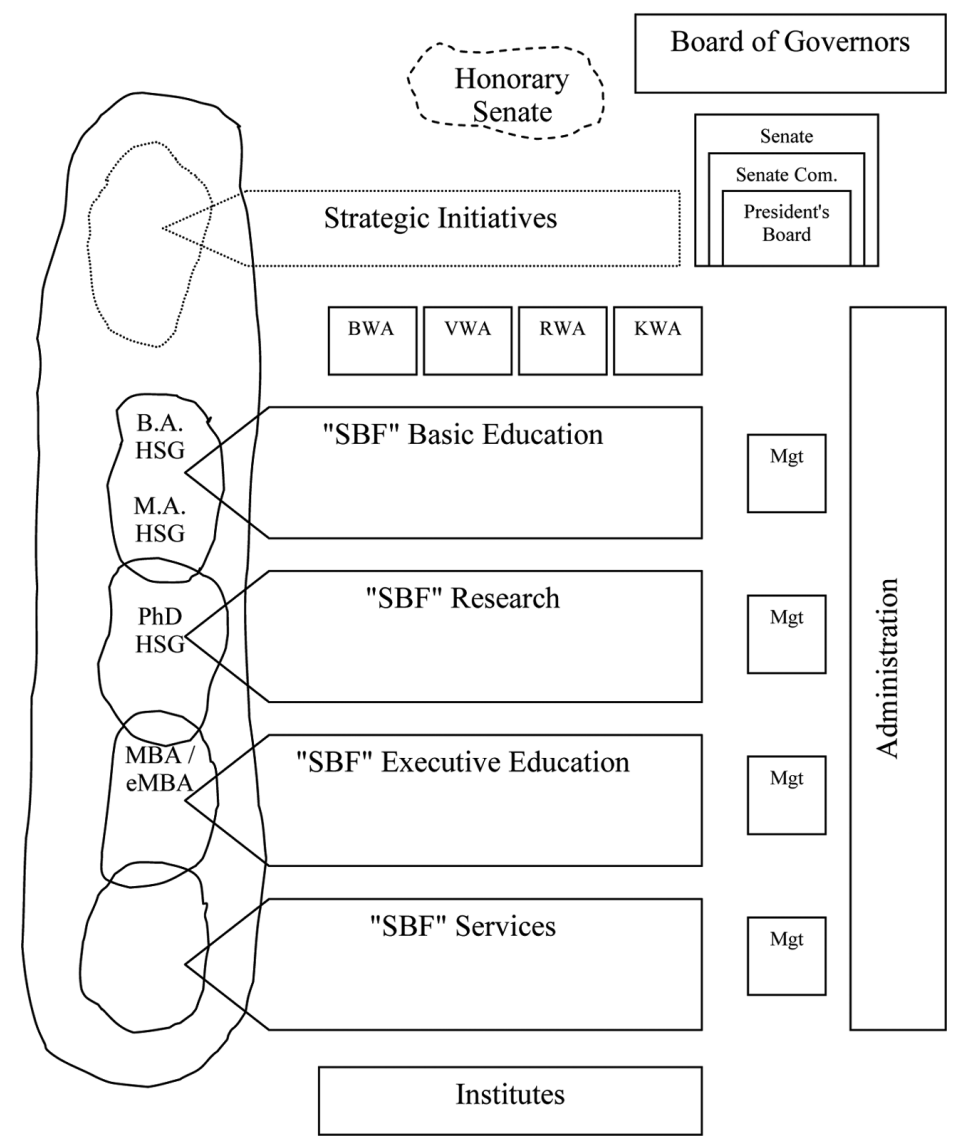

At first glance, we simply turned the organisational chart by an angle of $45^{\circ}$, so that the programs become systems 1 and the departments change to systems 2 , which describes their character remarkably quite well.

With this chart (Figure 2) we are able to find many further details.

The 'target markets' are lined out and even partially structured. The services to be provided are made visible. The systems 1 are all on the same recursion level. The systems 2 are enriched by the institutes and the administration, so these are made visible as well. The systems $3-4-5$ are also shown in more detail. The system 4 function is indicated.

Each system 1 has a management, which at present is loosely structured and of low visibility. The main deficit is that management functions are not assigned concretely and consequently to their respective recursions. 
The university has very pronounced systems 2 . These are the departments ${ }^{4}$ (even though they do not think of themselves in these categories), the institutes, and the units of administration. The institutes occupy an exceptional position. They are managed as profit centres, but they are not a full system 1 . In fact they primarily gather and coordinate a group of professors and their staffs. The main focus of the institutes falls on the two SBF executive education units and services. In SBF services the institutes come closest to system 1, but still have a substantial amount of coordination in their activities. Needless to say that there are further systems $2^{5}$ which do not manifest themselves as organisational units. These systems are not within the focus of this paper, because we want to fathom primarily the consequences for the organisation and not for the (IT) systems.

When discussing the structure of the university it looks as if many executive decisions are included in system 2 (while actually belonging in a system 3 ). The main task of a system 2 is 'to damp oscillation', that is, its chief concern is with implementing decisions that have already been made rather than helping systems $1 \mathrm{~s}$ respond to new environmental challenges. Considering this we seem to have a design mistake which might explain the problems that occurred when implementing the program heads in 2001 . But there is a further point to be considered: A professor participates in more than one system/function. Most of them are active in all SBF of the university, all are members of a department, most of them direct an institute, all of them are members of the senate, etc. This very possibly leads to a mingled allocation of duties and responsibilities.

The management of the total system is divided in four parts:

- the president's board

- the senate committee

- the senate (every professor is a member of this body)

- the board of governors.

In our view, the first three primarily represent systems 3 and 4 . The board of governors mainly performs system 5 functions. In certain cases the senate also has a system 5 characters. The honorary senate is composed of distinguished persons from the fields of politics, economics and business who are not on any other board of the university. Which functions and tasks this board should perform is open to question. We propose that they should be part of system 4 .

Strategic initiatives (like the NKL) are instigated by the president's board, which is the monitor of, and somewhat a stimulus to, the 3-4-homeostat.

An important $3 *$-function is not shown in the diagram. Quality development fills this function very well, performing intensive quality measurement, e.g., student evaluations of professors' classes. For a university outside accreditation agencies like EQUIS or AACSB are also part of system $3^{*}$. This unit makes sure that system 3 always has a very clear picture of what is going on in operations. At this time the focus falls on basic education.

On the other hand a centralised $3 *$-function is not that crucial for a university because every professor is part of operations by virtue of teaching and doing research. This design ensures adequate feedback. 


\section{Squiggly lines}

In the diagram above (Figure 2) the so called 'squiggly lines' (Beer, 1988, p.58) between operations deliberately are not drawn. For successful operation of the university, however, these communications are nevertheless decisive.

On the one hand, these denote the relations between students of different semesters and branches of study. Due to these relations a lot of information is exchanged and potential problems can thus be avoided. We experienced the effect of reduced exchanges of experience between students when initially implementing NKL step by step. It was necessary to invest a lot of effort and energy in measures of information and communication, simply to ensure half-decent operations of basic education under the new regime. As soon as there again were 'senior' students, the need for information and communication diminished. Information seemed to distribute itself 'automatically' within the student population again.

A second example of 'squiggly lines' are the professors themselves. By being involved in all four SBFs, they ensure an effective exchange of information which thus need not be organised separately.

On the other hand, one may not forget that these additional exchanges of information in many cases also distribute wrong information or even rumours, which are sources of many problems for management. We can tell by experience, however, that the advantages easily outweigh the negative effects.

\section{VSM-based analysis}

In the following steps of analysis we want to get even closer to VSM-logic and at the same time move away from the familiar organisational chart. The focusing of this analysis on the homeostats 'environment - operations' (A) and 'operations - management' (B) proved to be very useful (Figure 3).

Figure 3 Basic model

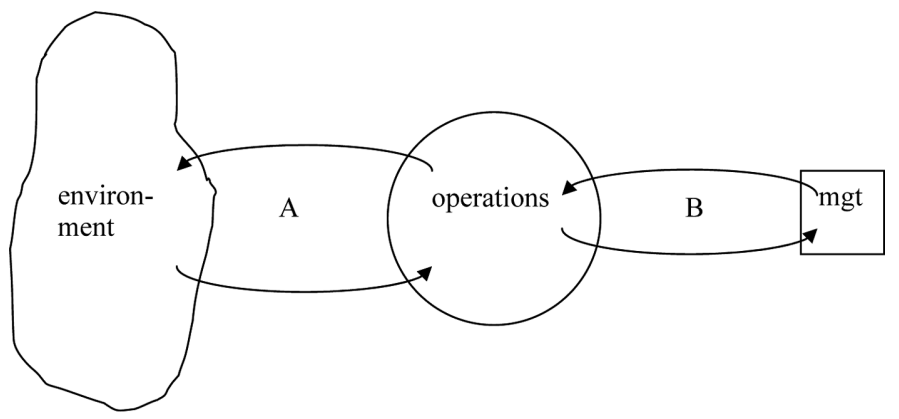

\subsection{Homeostat 'environment-operations'}

First of all we shall look at the homeostat 'environment - operations' by posing three questions: 
- How is the environment structured?

- How are operations structured?

- In which ways are their detail structures interlinked?

The findings of such analysis aid organisational design by showing where intensive communication is necessary between systems.

The answers to these three questions can best be given in the form of a table (Table 1). An intensive interaction is marked with ' $X$ ', a less intensive interaction with ' $x$ '. A blank field at a point of intersection indicates that between the two units or systems no interaction occurs at all (or that this group is not intended as a 'customer').

The actual analysis can be done pragmatically with little cost. Nevertheless it quickly shows the strengths and weaknesses of the situation.

Our overall conclusion is that the University of St. Gallen has designed its interface towards the market in an adequate way. The mapping of the business units to the market segments/customer groups is quite clear-cut. There are few common market areas, and the target groups are well assigned.

Table 1 Homeostat 'environment - operations'

\begin{tabular}{|c|c|c|c|c|c|c|c|c|c|c|c|}
\hline \multirow{2}{*}{$\begin{array}{l}\text { Parts of operations } \\
\text { Groups in the } \\
\text { environment }\end{array}$} & \multicolumn{3}{|c|}{ Basic education } & \multicolumn{2}{|c|}{ Research } & \multicolumn{4}{|c|}{ Executive education } & \multicolumn{2}{|c|}{ Services } \\
\hline & 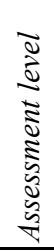 & 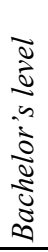 & 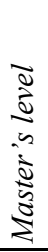 & 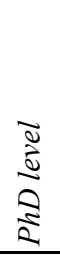 & 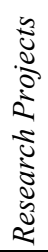 & $\stackrel{7}{2}$ & $\underset{\Omega}{\mathbb{Z}}$ & 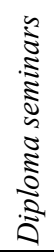 & 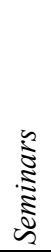 & 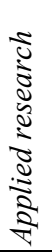 & 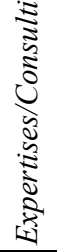 \\
\hline High School Graduate & $\mathrm{X}$ & & & & & & & & & & \\
\hline $\begin{array}{l}\text { Student on Bachelor's } \\
\text { Level (without Degree) }\end{array}$ & $\mathrm{x}$ & $\mathrm{X}$ & & & & & & & & & \\
\hline BA HSG & & $\mathrm{x}$ & $\mathrm{X}$ & & & & & & & & \\
\hline BA of other university & & $\mathrm{x}$ & $\mathrm{X}$ & & & & & & & & \\
\hline MA HSG & & & $\mathrm{x}$ & $\mathrm{X}$ & & & & & & & \\
\hline MA of other university & & & $\mathrm{X}$ & $\mathrm{X}$ & & & & & & & \\
\hline $\begin{array}{l}\text { Graduates with degrees } \\
\text { in non-HSG subjects }\end{array}$ & & $\mathrm{x}$ & $\mathrm{x}$ & $\mathrm{x}$ & & & & & & & \\
\hline PhD student HSG & & & & $\mathrm{X}$ & $\mathrm{X}$ & & & & & & \\
\hline
\end{tabular}


Table 1 Homeostat 'environment - operations' (continued)

\begin{tabular}{|c|c|c|c|c|c|c|c|c|c|c|c|}
\hline Parts of operations & \multicolumn{3}{|c|}{ Basic education } & \multicolumn{2}{|c|}{ Research } & \multicolumn{4}{|c|}{ Executive education } & \multicolumn{2}{|c|}{ Services } \\
\hline $\begin{array}{l}\text { Groups in the } \\
\text { environment }\end{array}$ & 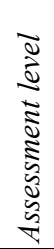 & 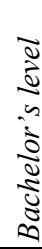 & 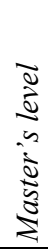 & $\frac{\bar{d}}{\frac{a}{2}}$ & 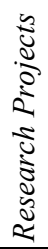 & $\underset{1}{\square}$ & $\underset{d}{Ð}$ & 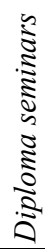 & 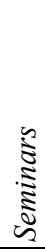 & 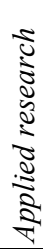 & 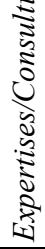 \\
\hline Junior faculty & & & & & $\mathrm{X}$ & & & & & & \\
\hline $\begin{array}{l}\text { Researcher of other } \\
\text { universities }\end{array}$ & & & & & $X$ & & & & & $\mathrm{x}$ & \\
\hline $\begin{array}{l}\text { Executive with less than } \\
\text { five years experience }\end{array}$ & & & & & & $\mathrm{X}$ & & & & & \\
\hline $\begin{array}{l}\text { Executive with more } \\
\text { than ten years } \\
\text { experience }\end{array}$ & & & & & & $\mathrm{x}$ & $\mathrm{X}$ & $\mathrm{X}$ & $\mathrm{X}$ & & \\
\hline Top Management & & $\mathrm{x}$ & $\mathrm{x}$ & & $\mathrm{x}$ & & $\mathrm{x}$ & $\mathrm{x}$ & $\mathrm{x}$ & $\mathrm{X}$ & $\mathrm{X}$ \\
\hline $\begin{array}{l}\text { Head of } \\
\text { HR/HR-Developer }\end{array}$ & & $\mathrm{x}$ & $\mathrm{x}$ & & & $\mathrm{x}$ & $\mathrm{x}$ & $\mathrm{x}$ & $\mathrm{x}$ & & \\
\hline
\end{tabular}

On the other hand, there are still a few overlapping areas, and there is some room for improvement. For example, quite a few uncertainties and questions remain concerning admission into the respective programs. The reason for this is the different views of those in charge of basic education and executive education. Within their markets (on the lower recursions) the views are absolutely reasonable. That is, in basic education an academic record is absolutely necessary for quality reasons, whereas in executive education a more liberal policy can work quite well. A market for education at the university level may well exist for experienced professionals who never had the chance to acquire a BA.

Finding a common view (on the higher recursion level) leads to the problems mentioned earlier. Finally we can observe that the interface towards enterprises is served by too many different units.

As a consequence we may propose the following two measures:

- The university needs either a centrally implemented admissions policy, which defines distinct borderlines for the programs, or a central admissions office (for both SBFs).

- The university needs a contact person for enterprises who is competent and clearly visible. This position would bundle and coordinates internal communications and supplies orientation to enterprises.

Further consequences come from deepening the analysis of this interface. 


\subsection{Homeostat 'operations - management'}

Analysis here follows the same pattern. ${ }^{6}$ This time we inquire into only the intensity of communication between operations and management. The line of sight starts at operations (again 'outside in').

Table 2 Homeostat 'operations - management'

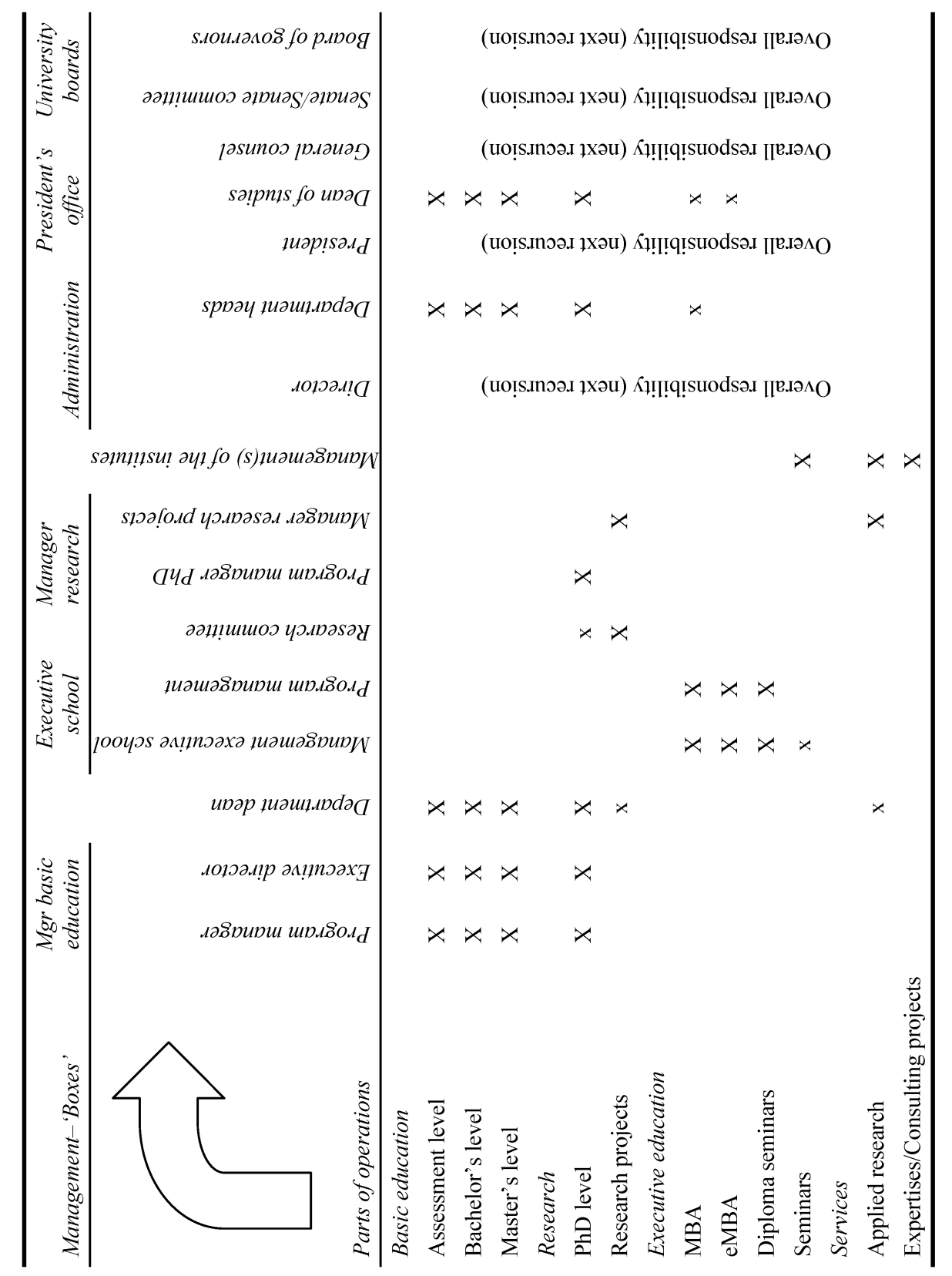


The findings are less positive than in the first part. In basic education we find that (too) many parties are claiming influence without being made responsible for consequences. The program head in fact is the manager of a system 1, but he has to arrange things with three additional parties. Most critical in our view is the management of departments. In their perception they still possess internal cohesion and the right to pull all the strings by being the responsible systems 1 . Here we must expect conflicts, and we will have to do something organisation-wise. The dean of studies and the department heads in administration understand themselves in this context as systems 2 , so that here we can expect fewer and more constructive conflicts.

For the PhD Programs the points made above are equally valid.

The responsibility for research projects is assigned to the project managers. What causes problems is the management of research as a whole. This finding does not actually emerge from a VSM-based analysis, but it is known from other considerations and is experienced in the daily routine. Probably it could be made visible on a higher recursion level. In certain cases it is in fact quite difficult to draw a clear borderline between basic and applied research. For this reason it could be important and useful to bring the management functions of these two activities closer together.

Executive education is organised quite well and the responsibilities are clearly assigned.

The institutes show clear assignments in matters of direct business activities. The fact that institutes are managed as profit centres supports this finding. The potential interference with (basic) research is mentioned above.

This analysis has taught us that certain management functions must be related to a higher recursion level which has an overall responsibility.

\section{Next step in the discussion}

When discussing possible new organisational structures for the University, the management always looked for a way to avoid the matrix structure, which began to appear. While it is true that this structure surely looks impressive and can integrate several different views at once, at the same time it maximises the need for communication within the organisation, meaning that communication must occur (not simply may occur). In an enterprise this leads to a maximum of meetings, committees, e-mail and other forms of communication.

The organisational structure we started with could be identified as a functional one. Actually it comprised in principle four departments, each representing an academic discipline. The matrix structure discussed already above can be understood as a development of this original structure that incorporated the market side as a second dimension. But it shows the disadvantages already discussed: It asks for highly elaborate rules and regulations which govern the communication and cope with decision making in cases of conflict. In place of this, a solution which focuses entirely on the market's or customer's view is much simpler. In term of the 'VSM language' we could talk of completely implemented systems 1 . In the following proposal for a new organisational structure of the university we attempt to carry this further step into a so called divisional structure. How well it will work only the future will tell. For the time being we can only discuss our expectations of possible future effects. 
Interpreting the following VSB-based representation, one must take into account that it is an illustration of the organisational principle and not a detailed diagram of the actual organisational structure comprising all participating units. There will be more than just one school, and the Executive School is found only once, whereas in fact there are about 30 institutes and research centres at the University of St. Gallen. The intention therefore is not to draw up an organisational chart but to illustrate the organisational principle. In looking at the following illustration (Figure 4) this must be taken into account.

In the structural concept presented here 'schools' are established as a new concept. These units, of which four to six are planned, embrace all activities in the fields of basic education and research. Therefore they deal with the publicly funded activities of the university.

Figure 4 Target organisation of the University of St. Gallen (VSM-based representation)

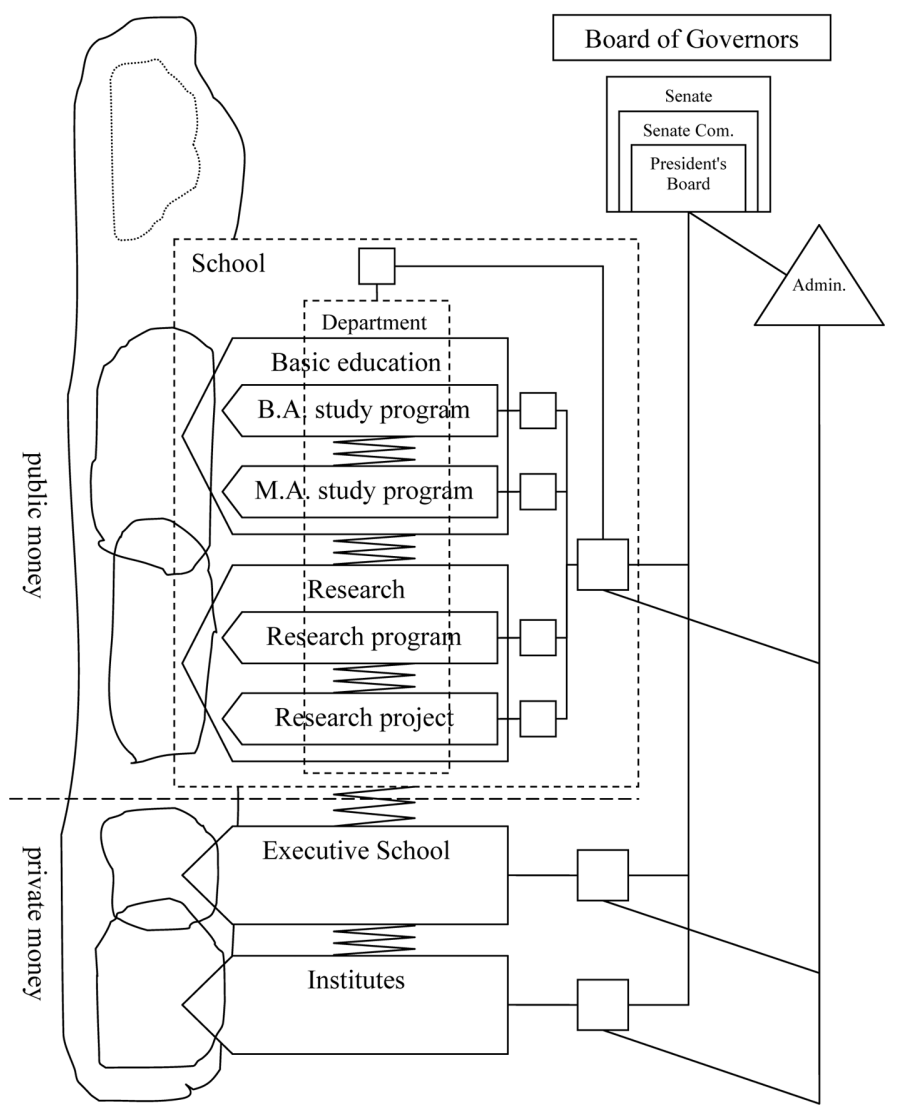

The privately financed activities, i.e., the Executive School and the business activities of the institutes (so far we have always addressed these systems 1 as services), are not affected by this new structural concept. It is still the intention to equip these units with as much autonomy as possible, so that they can continue to move on the free market in an agile and customer-oriented way. In consequence the Executive School has its own management (an academic dean and two executive directors) and administrative units (system 2), which provide the requested services for this part of our organisation. To have 
a separate administration is very sensible, because neither the general rules of business nor the internal processes match those of basic education. The institutes are already run as small enterprises anyway, which in most cases works very well. On the part of the university, which is financed privately, there is no need for further change.

With the proposed structural concept we achieve a solid and coherent separation between the publicly funded aspects and the privately financed activities. This is highly expedient, because, depending on the funding, totally different business and/or process mechanisms have to be applied.

In basic education the study programs are still systems 1 , which have the real-market or customer exposition. These programs are the units to which the customers - in our case the students - assign a perceivable product, e.g. a university degree with a precise profile and occupational image. Our students come to St. Gallen precisely because of these university degrees and not because of other features, e.g., the reputation of our academic staff or our excellent research. Needless to say, these features also play a certain role, but we are convinced it is only an indirect one. According to the concept the study programs are associated with a school. The schools therefore shift from the present departments with a primarily disciplinary focus (systems 2 ) to market oriented units (in the sense of systems 1). The programs are led by an academic director (who is a professor); he in turn is supported by an administrative director (system 2), who need not necessarily pursue an academic career. The program managers report directly to the dean of the school.

The second task of a school is to do research. Organisationally, this happens in research programs and research projects. Research programs are major initiatives. Here we can mention the planned strategic research initiatives of the university. Research projects, on the other hand, can be of rather different sizes and scopes, because in principle they depend on the dedication of a single scholar or chair in a decentralised unit. To what extent the program directors and project managers directly report to the dean in a classical manner is still an open question. Being a decentralised issue, mostly done 'bottom up', research has to be dealt with in a prudent way.

Between the two business fields - basic education and research - further vertical coordination and adjustment is needed. To a great extent this already occurs due to the degree course scheme, through the combination of functions, ${ }^{7}$ the integrative model - which is very important for the scholars in St. Gallen - and through informal contacts. The 'new departments' will make an important contribution as systems 2 . They must not be confused the existing departments, which will merge into the schools. Such a 'new department' will stand for the disciplinary view, which in the new structure is missing so far. As an option, a study program may be assigned to a department, so that it can be represented within the academic discipline. In the new structural concept the disciplinary view therefore still appears, although a bit weaker.

To summarise, the dean of a school has the following duties with the corresponding responsibilities. He accounts for the programs and projects in basic education and research. In doing so he has to mind the dimensions of cost and quality. He can promote the development of content in the relevant academic discipline(s) using the department structure.

Regarding structures on the next recursion level, the administration remains the most important system 2. It will continue to be managed as a single unit, because this organisational principle has produced rather good results so far. 
At the University of St. Gallen it is very important to bear in mind that systems 2 play a central role due to their specific situation in the academic structure. An organisation of professionals, which a university surely constitutes, is at any rate decentralised. To cope with this, effective systems 2 are needed, most of them probably not manifesting themselves in structural arrangements. So a shared academic model (e.g., the 'St. Galler Management Modell'), the integrative approach to the conception of our curricula, the preference in financing systemic and interdisciplinary research projects etc. must be looked at as system 2 functions. At the end of the day even the high exposure of our scholars to companies and practitioners can be looked at as a kind of system 2 . This aspect may be a little surprising, but we hold the view that the real management problems are per se integrative and interdisciplinary. If therefore a professor (being a system 1 in this case) wants to be respected by practitioners as a relevant source of knowledge, he or she must be much more than just a representative of a narrow academic discipline.

For the general management of the university - from president's board up to the board of governors - no further adjustments are needed. Their structure and responsibilities can be left as they are.

\section{Epilogue}

What is different, then, when we look at an organisation or a structure with 'VSM glasses'? What factors improve when one does organisational work with this model in mind? Even in formulating an answer to this question - this is not really surprising - VSM can serve as a useful tool.

The system we look at in order to answer these questions contains two subsystems: the 'system to be organised' and the 'system that organises' (Figure 5).

Figure 5 Benefits of VSM in organisational work

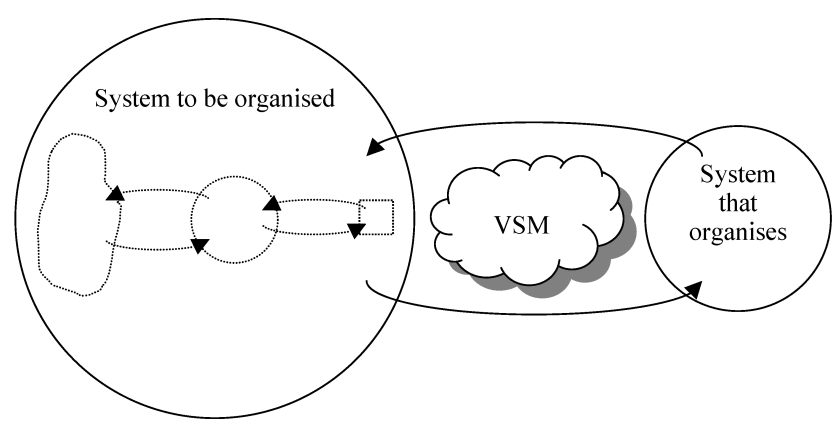

In our case the first system is the university, which we analyse, model and finally design in order to reach a higher degree of effectiveness. The second system is the manager or the management team, in our case the president's board. VSM itself provides us with a language in which we can reflect ourselves and our actions (indeed this is a system 4 function). VSM is not an additional system, but it stands 'above' the system we are working in. In a substantial way it organises our perception and therefore our constructs of the structures within which we are moving. Provided that we apply it, VSM has a considerable impact on our organisational work. 
Concluding this contribution we discuss this (positive) impact and look at it more precisely. By doing this we propose to distinguish the two points of view discussed just above. The first looks from the 'system that organises' to the 'system to be organised'. The second viewpoint aims in the opposite direction. Rather often the arguments of the one are simply the reverse of the other; even so, we still propose to stick to this differentiation.

We now discuss the two views. The issues to be considered in each line of vision are as follows:

\section{1 'System that organises' to the 'system to be organised'}

Focus on the purpose of the system/the value added/the customer: According to VSM the organisational work always starts with the purpose of the system. VSM even requires that the customer or the purpose can be identified and is visible on the graphical representation of the system in focus. We hold the view that this confers a big advantage, because by doing so one never forgets what it is all about.

Necessity of segmentation (finding the systems 1): In strategy work this step is obvious. In our view, organisational work does not include this step consequently enough in the process of analysing and designing a good organisation. VSM forces one to take this step.

Proper distinction of recursion levels: The true reason for quite a few control problems lies in mixing up recursion levels. In this respect VSM asks for coherent structures. As a consequence the usual control or competency problems, which may still arise, will be more easily identified.

Proper distinction of management functions $(1,2,3,3 *, 4,5)$ in the sense of a checklist for a sound analysis: Since VSM describes all necessary and sufficient functions of a viable system, when doing an analysis (or a design) nothing can be forgotten. The model ensures that everything of relevance is taken into account. There is an additional benefit: organisational units or issues which do not have a real purpose within the system remain unconsidered.

Good communication tool/powerful visual language: ${ }^{8}$ When a manager has a good organisational idea, he or she still has to communicate this concept to the members of the organisation. Only when this is done in an effective manner will they be able to act in an autonomous and still holistic way, and the organisation be able to generate the needed requisite variety to cope with the environment. VSM helps in this aspect with its coherent, simple visual language.

The individual understands his or her position in and contribution to the organisation: Being responsible for a task, one needs to recognise one's proper position within the logic of the organisation. By doing this, a VSM-based representation accounts for a lot more than does a traditional organisational chart. Based on this concept an administrative department, for example, will correctly think of itself as the backbone of an enterprise. Furthermore, individuals usually play roles in more than one system. It is very helpful for them to distinguish which role they are playing in a given system. 
Organisational conceptions and measures concentrate right from the start on the issue of 'designing communications': Organising actually is working on the communication structures between the members in- and outside an enterprise. VSM itself is about communication.

From a manager's viewpoint it is clear that VSM is a highly useful model for organisational work.

\section{2 'System to be organised' to the 'system that organises'}

The right questions are asked, more precisely the right things or issues are analysed: VSM makes sure that the right questions are asked. By the same token, this also means that it avoids asking the wrong ones. Therefore VSM increases both the effectiveness and efficiency of organisational work.

The completeness of an analysis is ensured: VSM describes all necessary and sufficient functions of a viable system. It therefore it is able to ensure the integrity and the accuracy of an observation.

The behaviour of organisations or of parts of it can be understood better: Looking at an organisation with a capable model leads in consequence to a better understanding of what is found and of what is actually happening. For questions of management VSM leads to suitable interpretations of the analysed structures. The limitations of VSM are reached as soon as the 'inside of operations' come into view.

The feedback information of an organisation can be interpreted in a targeted manner: Having a capable model at hand, a manager is able to reinterpret the signals of the organisation in a targeted and effective way (in the sense of an effective attenuator). Irrelevant information can be filtered out, and relevant signals can be amplified and analysed in more detail. VSM provides the filter for this task.

Malpractice or loopholes are detected at once and interpreted correctly: The model helps in detecting mistakes and structural gaps and - at the same time - gives directions for a sound design.

One inherent limitation of VSM still remains: The model does not provide real answers to the configuration of operations. But when it does, they concern management-only issues. Actually the VSM was not designed as a tool to use on the configuration of operations, but professionals need such tools in their practical work. This limitation - as soon it is properly understood - can be taken into account rather well. For these tasks we have to draw on other instruments and concepts, e.g., process reengineering. As soon as we are talking about questions of control and development again, VSM is extremely helpful and effective.

We have to consider that the use of VSM in the daily work of an organiser or a manager implies rather detailed knowledge of the model. Without this knowledge Stafford Beer's original diagrams make no (additional) sense to the observer; in the worst case they rather disorient him instead of providing added value. To be able to use these models training is needed. ${ }^{9}$

Taking into account all these arguments, we certainly still can come to the conclusion that VSM and VSM-based representations of organisations contribute greatly to practical organisational work. 


\section{References}

Beer, S. (1988) Diagnosing the System for Organizations, Wiley, Chichester.

Ulrich, H. (2001) Das St. Galler Management-Modell, Haupt, Bern.

Rüegg-Stürm, J. (2002) Das Neue St. Galler Management-Modell: Grundkategorien einer integrierten Management-Lehre, Haupt, Bern.

\section{Notes}

${ }^{1}$ http://en.wikipedia.org/wiki/Bologna_process

${ }^{2}$ Translation: New conceptual design of basic education.

${ }^{3}$ In this illustration we allocate the various system components according to the original diagrams of Stafford Beer (1988, p.2), in the way he proposed them for VSM. But we are using slightly different symbols. For operations we use a process symbol. We also do not draw all the connecting lines, even though we are quite aware of their importance. All these changes should improve the readability of the diagrams. We have learned that the 'original' diagrams are not understood without deeper knowledge of the work of Stafford Beer.

${ }^{4}$ BWA: Department of Management, VWA: Department of Economics, RWA: Department of Law, KWA: Department of Humanities.

${ }^{5} \mathrm{We}$ are referring e.g., to the class schedule application, and to many other internet sites and diverse committees, which all have big coordinative effects. At our university we also operate a learning management system, on which we provide learning content and IT-supported learning offers.

${ }^{6}$ One of the main advantages of working with VSM-based analysis and design in organisations lies in the fact that you can use a relatively small number of tools and basic principles over and over again. We are not forced to use a different complicated tool or method on every different problem. In effect, VSM is the 'Swiss Army Knife' of the organiser.

${ }^{7}$ As a result of our present organisation every academic staff member administers quite a few organisational roles. He or she is a teacher, does research, is director of an institute, member of a committee in the university management, etc. Sometimes this makes things more complicated; on the other hand it is a very powerful system 2 and helps a lot in coordinating things within our rather complicated organisation.

${ }^{8}$ Working with managers of all kinds, who normally did not know VSM but were still quite experienced due to their practical work, I have found again and again that VSM-based representations of organisations are understood instantly by these professionals.

${ }^{9}$ I remember very well the answer of Stafford Beer, when he was asked questions about the basics of VSM: "Read those bloody books!". 